\title{
Determinants of Innovative Behaviour in the Hotel Industry: A cross- Cultural Study
}

\begin{abstract}
The present study develops a conceptual framework that sheds light on whether institutional pressures (i.e., normative, mimetic, and coercive) and corporate support can improve innovative behavior across different societies and the moderating role of national cultural dimensions on this link. Our study validated these arguments empirically using data from the 2018 Global Entrepreneurship Monitor (GEM). Data were collected and analyzed from 2,618 respondents. Data were collected through a questionnaire survey of full-time non-managerial employees selected, from different departments of various four- and five-star hotels across five economically and culturally different societies (UK, UAE, Germany, China, USA). Our results indicated that both institutional pressures and corporate support have positive influence on employees' innovative behaviour. Furthermore, Hotels in cultures with high levels of individualism and low levels of uncertainty avoidance, power distance, and masculinity will indicate higher levels of innovative behaviour in response to corporate support programs. While, hotels in nations with high levels of power distance, collectivism, uncertainty avoidance, and masculinity will indicate higher levels of innovative behaviour in response to normative, mimetic, and coercive pressure. These findings provide important implications for innovative behaviour by developing and validating a multilevel model empirically in the hospitality context.
\end{abstract}

\section{Keywords,}

Employees' innovative behaviour, institutional pressures, corporate support programs; CrossCultural Study. 


\section{Introduction}

Since the times of its emergence in the late 1970s, business and their stakeholders have paid attention to innovation as a source of competitive advantage and firm growth (Anning-Dorson, 2018; Brem et al., 2016; Salunke et al., 2019). Innovation and innovative behaviours have long been considered as one of the key solutions for companies to effectively respond to rapidly change of business environment, and achieve competitive advantage (Damanpour and Aravind, 2011; Dusana et al., 2016; Herrera, 2015; Le and Lei, 2019; Nguyen et al., 2019; Petrakis et al., 2015; Rodríguez-Victoria et al., 2017; Skinnarl et al., 2014; Urbancova, 2013).

Tourism and hospitality firms work in a highly competitive environment which is described by continuous transformation (Aldebert et al., 2011; By and Dale, 2008; Kale et al., 2019; Lam and Law, 2019; Massidda et al., 2017; Orfila et al., 2009; Stamboulis and Skayannis, 2003; Xiang et al., 2015). Thus, to gain competitive advantage, these firms rely on their innovativeness in attaining higher service quality and lower costs that meet their consumers' needs and wants (Amarakoon et al., 2018; Anning-Dorson, 2018; Chen et al., 2009; Ireland and Webb, 2007; Lengnick-Hall, 1992; Salunke et al., 2019; Shepherd and Ahmed, 2000; Weerawardena and Mavondo, 2011).

Employees' innovative behaviour plays a key role in consumer service-oriented firms such as hotels, wherein these firms motivate their employees to be more innovative and creative in order to meet their changing consumers expectations, requiring them to use their capabilities and skills to provide new ideas that can improve consumer service quality (Afsar and Badir, 2017; Chou and Walker-Price, 2018; Dhar, 2015; Galende and de la Fuente, 2003; Hansen and Pihl-Thingvad, 2019; Sundbo et al., 2007). Therefore, investigating the determinants of employees' innovative behaviour constitutes an important research area, particularly in the context of hospitality. 
Several studies have investigated the influence of corporate support and institutional pressures (i.e., normative, mimetic, and coercive) and revealed that these factors are key drivers of innovative behaviour (e.g., Dhar, 2016; Domínguez-Escrig et al., 2019; Dubey et al., 2019; Engelen et al., 2018; Kauppi, 2013). Motivated by anecdotal evidence on successful innovations that non-managerial employees have proposed, firms expect significant untapped potential for innovation in their workforces (De la Pena et al., 2016; Kuratko, Morris, and Covin, 2011). Therefore, some firms have established corporate support programs for innovation, such as the "i-mentor" program at Whirlpool and Google's "20\% Innovation Time Off' (Baldwin, 2012; Roosen \& Nakagawa, 2008). In examining these support programs, academic research finds that corporate support can facilitate innovative employee behaviour (e.g., Chandler, Keller, and Lyon, 2000; Engelen et al., 2018).

However, these studies do not account for nation-level drivers that might impact the strength of the relationship between corporate support and employee's innovative behaviour. Since cross-cultural management research shows that management techniques' effectiveness varies across the globe (e.g., Newman and Nollen, 1996), the absence of insight into the possibility of nation-dependency is problematic, especially because resource-intensive corporate support programs are often rolled out globally, as in the case of Whirlpool and Google. Academic crossnational research needs to determine whether these programs are universally effective or are bound to specific national circumstances.

This research gap is not surprising because most studies on innovation focused on single countries (Engelen et al., 2018; Strese, et al., 2016). This study focuses on five economically and culturally different societies (UK, Germany, and USA) (individualistic societies), and (UAE and China) (collectivistic societies). Thus, this study seeks to address two research questions: (1) Does the influence of institutional pressures (i.e., normative, mimetic, and coercive) on employees' innovative behaviour vary across societies? And (2) Does the 
influence of corporate support (i.e., budget, time, and advice) on employees' innovative behaviour vary across societies?

This paper develops a theoretical model to shed light on whether corporate support programs and external pressures can foster employees' innovative behaviour across nations in the hospitality industry. Based on extant research that indicates that corporate support and institutional pressures has a significant influence on innovative behaviour (e.g., Dhar, 2016; Domínguez-Escrig et al., 2019; Dubey et al., 2019; Engelen et al., 2018; Kauppi, 2013), we argue that hotels can foster employees' innovative behaviour by establishing corporate support programs and responding to the external pressures. Drawing on extant cross-cultural management research that indicates that the impact of management practices can be constrained if these practices do not match employees' cultural values (Jiang, Colakoglu, Lepak, Blasi, and Kruse, 2015; Lachman, Nedd, and Hinings, 1994), we also argue that national culture plays a significant role on the strength of the relationship between corporate support programs, external pressures and employees' innovative behaviour.

Our study contributes to the literature in two major ways. First, we contribute to innovation research by extending research on how individual employees can be motivated to act innovatively-especially by deepening knowledge on the relationship between corporate support, external pressures, and innovative employee behaviour. Since direct-effect models dominate this research stream (Stock, 2015), we add a fit perspective by identifying situationdependent drivers of individual employee behaviour at the national level, increasing the precision of research models in the hospitality industry. Therefore, our research offers implications for hotels seeking practical ways to improve their employees' innovative behavior and thus the results promote the idea that hotels should invest in innovative activities. 


\section{Literature review and conceptual framework}

\subsection{Institutional theory and innovative behavior}

Based on DiMaggio and Powell (1983), the institutional theory seeks to address the question of why all firm in a specific field incline to look and act the same. Scott (1995, p.274) defined institutions as "regulative, normative and cognitive structures and activities that provide stability and meaning for social behaviour". Examples of these institutions comprise customs, culture, laws, social norms, ethics, and regulations. Based on Currie (2012, p. 129), "institutional theory is a multi-level construct spanning the individual, organizational, and the organizational field levels of analysis." It promote the process of technological innovation in the organizational context (Ahmadi et al., 2017). Based on this theory, institutions include three types of pressures: normative, mimetic, and coercive (DiMaggio and Powell, 1983; Greenwood and Hinings, 1996). Normative pressure is defined as the professional practices and standards developed by training and education methods and the employees movements between organisations (Garud et al., 2007). Mimetic pressure represents the copying or imitation of other successful firms when a firm is not sure about what it should do. Coercive is a pressure from entities that have resources on which a firm depends.

Institutional theory suggests that institutional pressures affect organizational members' behaviour and cognition (Scott, 1995). Drawing on institutional theory, firms form themselves to enhance their stakeholders' perceived legitimacy (Ruhanen and Whitford, 2018). This is because of procedures, structures, and regulations forced by regulatory bodies on firms (Dubey

et al., 2018). Prior research indicated that firms might be imposed to switch their structure due to competitive pressures, governmental pressures, or adapt with normative standards generated by accreditation organisations (de Leeuw and Gössling, 2016; Sila, 2007; Yang, 2018). 
Institutional research on organisational innovation is concerned with how the institutional environments in which organisations operate influence the creation and diffusion of management practices (dos Santos et al., 2020). Legitimacy is the central concept that explains the relationship between organisations and their institutional environment (Damanpour 2014; Uzunca, Rigtering, and Ozcan, 2018). Organisations, therefore, both actively seek and are passively influenced by the effects of legitimacy, which is defined here as the perception that a set of actions is considered adequate inside a given system of norms, values and beliefs (Suchman 1995; Wei et al., 2017). Organisational persistence depends on the social perception of the legitimacy of their actions (Kiefhaber, Pavlovich, and Spraul, 2020).

Hotels exist and operate within specific legal frameworks, with norms and regulations influencing their organisational practices, structure and behaviour. Hotels respond to these pressures by adapting their structures and actions, leading to more homogeneity (DiMaggio and Powell 1983; Zhang et al., 2019). Non-legal coercive pressures also exist, such as demands from stakeholders for more socially responsible practices, which may also influence organisational behaviour. Coercive isomorphism takes place, therefore, when organisations experience pressure from other organisations or from the expectations that exist in a given social environment (DiMaggio and Powell 1983; Zou et al., 2019).

Mimetic isomorphism takes place when hotels imitate the practices of their peers. This practice is usually associated with high degrees of uncertainty (DiMaggio and Powell 1983; Zvolska, Palgan, and Mont, 2019). The main advantage of mimetic behaviour, also known as modelling, is the low cost associated with the acquisition of tested organisational solutions (Wennberg and Holmquist 2008). Mimetic processes may lead to innovation, particularly when an attempt to copy a practice leads to the acquisition of new attributes for an organisation (Bohnsack et al., 2020). Finally, normative isomorphism is a consequence of professional regulation and formalisation (DiMaggio and Powell 1983). Standardised training and education via academic 
courses, combined with professional relational networks, exert isomorphic pressure on organisations.

Recent research on institutions has highlighted the role of legitimacy for the diffusion of organisational innovations. Mair and Reischauer (2017) propose that legitimacy plays a key role in the diffusion of organisational practices in the emerging sharing economy. Reischauer (2018) argues that the discourse behind industry 4.0 as a revolutionary organisational innovation is better understood through the role of discourse and legitimacy in institutionalisation. Kasperavičiūtė-Černiauskienė and Serafinas (2018) investigated how perceived legitimacy influences the diffusion of organisational innovations and the role of certifications. Berrone et al. (2013) investigated how normative pressures influence the diffusion of green innovations, and their findings suggest a positive correlation between normative pressures and the diffusion of green innovations. Liao (2018) also investigated the relationship between normative pressures and green innovations and identified a positive correlation. While all these studies have made valuable contributions, they focus on a specific innovation (green innovation, industry 4.0) or on an industry or business model (sharing economy). These studies do not clarify the association of specific institutional pressures (coercive, mimetic and normative) with employees' innovative behaviour.

According to the institutional theory, prior studies revealed that mimetic forces from competitors have significant influence on innovation (Adebanjo, Teh, and Ahmed, 2018; Wang, Font, and Liu, 2020). Despite previous research on innovation adoption does not clearly utilise institutional theory, few studies revealed that innovation adoption in the organisational scope is significantly affected by competitors' pressures. For example, Ouyang, Wei, and Chi (2019) revealed that when firms see other firms in the same industry adopt the innovation, these firms feel pressures to use innovations. Moreover, potential adopters of innovations are influenced 
by competitors pressures (Shin, Perdue, and Kang, 2019; Wikhamn, Armbrecht, and Wikhamn, 2018).

Regarding employees' innovative behaviour in the hospitality field, coercive pressures arising from government would affect the innovation adoption (Binder et al., 2016). Consistent with previous research of innovations adoption, Sherer et al. (2016) utilised the institutional theory to examine the influence of external pressures on innovation adoption. However, prior research revealed that institutional theory has paid more attention to persistence and homogeneity, with less focus on the significant influence of interest and agency in forming action (Nguyen, 2018). To address this limitation, previous studies have comprised intraorganisational dynamics within the institutional theory model (Dubey et al., 2017).

Therefore, this study adopts a distinctive approach to analyse the determinants of employees innovative behaviour in the hotels industry, by proposing and empirically testing an integrated model, with contributions from well-grounded theories, namely the institutional theory and the fit theory. These theories have received substantial empirical support in explaining innovative behaviour (e.g., Cheffi and Abdennadher, 2019; Engelen et al., 2018; Fuentelsaz et al., 2018; Geels, 2004; Laukkanen and Patala, 2014). The proposed model seeks to take advantage of the validity, parsimony and reliability that these theories provide as determinants of innovative behaviour in order to improve explanatory and predictive power. Indeed, besides the constructs derived from these theories, national culture were added to the model, since researchers have pointed out that their roles in the context of innovation are still unclear (Engelen et al., 2018; Tian et al., 2018).

Prior research indicated that pressures caused by governments are key drivers of innovations adoption (Dubey et al., 2019). In the adoption of innovation, the coercive pressures arise from regulatory bodies (Grissemann et al., 2013). Where government has a significant influence on 
business practices and polices (Liang et al., 2007), coercive pressures are more likely to arise from governments. Therefore, the present study argues that coercive pressures directly stimulate employees' innovative behaviour in the hospitality context (See figure 1)

\section{Insert Figure 1 about here}

Normative pressure can come from media outlets, peer organisations, professional organisations, and other channels that companies identify to benchmark business outcomes and practices (Dubey et al., 2017; Nair and Prajogo 2009). In the hospitality industry, normative pressure can come from the social expectations placed on an organization by its stakeholders, such as residents and non-governmental organizations (Kassinis and Vafeas, 2006; Wang et al., 2020), resulting from industry standards set by an industry association (Berrone et al., 2013) and customers (Manaktola and Jauhari, 2007). Prior research found that normative pressure has a significant influence on innovation adoption (Lee and Dawes, 2005; Obal, 2017). Recently, Wuttke et al (2019) revealed that normative pressure is a key driver of innovations adoption. Therefore, the influence of normative pressure on employees' innovative behaviour would also hold when considering initiatives similar in scope and form such as innovative behaviour.

Another important mechanism of institutional theory, mimetic pressures was utilised as a key driver of the adoption of innovations (Nair and Prajogo, 2009). Mimetic pressure forces organizations to learn about their competitors' practices and to follow suit when others gain a competitive advantage by implementing eco-innovations (Kasim, 2007; Lewis and Harvey, 2001). Companies incline to imitate other companies that are peers (Cajaiba-Santana et al., 2020). For example, previous research revealed that mimetic pressures influence on innovation adoption (Wang et al., 2020). Scholars indicated that firms imitate other firms in the same industry concerning the adoption of innovation (Dubey et al., 2017; Kauppi, 2013; Liang et al., 2007). Despite there is a scant of research investigating the influence of mimetic pressures on 
innovative behaviour, institutional theory as well as hospitality literature propose that these effects should hold in the hospitality field (Wang, Font, and Liu, 2020). Therefore, the authors suggest the following hypotheses:

H1. Institutional pressures (i.e., normative, mimetic, and coercive), positively influence employees' innovative behaviour in the hotel industry.

\subsection{Corporate support programs and innovative behaviour}

Prior studies indicated that corporate support programs such as immaterial and material resources programs are crucial for developing employees innovative behaviour (Birdi et al., 2016; Engelen et al., 2018; Farh et al., 2007). Firm can provide their employees with variety of support programs in terms of advice, time, and budget (Engelen et al., 2018). Providing employees with time can help them to have enough time to work on developing innovative projects and ideas. When providing them with budget, employees can use these funds to develop a prototype (Ekvall and Ryhammar, 1999; Engelen et al., 2018). Advice is defined as supervisor or any member within the firm who provide employees with advice regarding the technological, economic, or market aspects of an innovative endeavour (Birdi et al., 2016; Engelen et al., 2018). Firms provide their employees with these types of resources (i.e., advice, time, and budget) according to the bureaucratic leadership or automatically such as firms can have general rules for employees to use a certain time of their work time to develop, generate, and implement innovative ideas. Innovative employees engage in complex and non-trivial tasks beyond their regular tasks that require persistence and creativity (Bammens, 2016) and face barriers to their innovative behavior, including lack of time, knowledge, cooperation from other firm members (such as supervisors and experts from other departments), and energy (Anderson et al., 2014; Hornsby, Kuratko, \& Zahra, 2002; Janssen, van de Vliert, \& West, 2004). Therefore, clarity about what motivates them to engage in innovative behavior is necessary in order to determine the potential of management practices like corporate support programs to 
increase such behavior. We argue that corporate support programs for innovation, such as programs that provide material and immaterial resources so employees feel that innovative initiative is enabled and encouraged, are an important lever for innovative behavior. Corporate support programs can manifest in terms of providing time, budget, or advice. When time is provided, an employee may work a certain part of his or her regular working time independently on innovative projects. Providing budget can include access to financing (e.g., funds to build a prototype) or manpower (e.g., capacity from other departments' experts).

Corporate support program plays an important role in developing and appreciating employees (Farh et al., 2007), make them feeling supported and valued (Bammens, 2016; Wayne et al.,1997). This innovative climate improves employees' confidence in their capabilities to develop innovative behaviour (Bammens, 2016). Birdi et al. (2016) found that corporate support programs influence employees' innovative behaviour. Employees who work in an innovative environment and receive support from their supervisors and other members of the firm are more likely to develop innovative behaviour. In support of this notion, Engelen et al. (2018), revealed that corporate support programs have a significant influence on employees' innovative behaviour. Therefore, the authors suggest the following hypotheses:

H2. Corporate support programs (i.e., budget, time, advice) have a significant influence on employees' innovative behaviour.

\subsection{The role of national culture}

Based on fit theory, this study argues that corporate support is more effective in driving employees' innovative behaviour when the support is compatible with the employees' preferences. Kristof (1996) refers to this perspective as the "needs supplies" perspective of the fit theory. Cable and Edwards (2004) find that, when employees' desires and needs are fulfilled, 
there is less conflict and employees are more likely to act in ways in which management practices are designed to encourage them to act (Eisend et al., 2016; Markman and Baron, 2003). This notion is in line with Klein and Sorra's (1996) argument that employees' adoption of innovative work methods (as concrete corporate support mechanisms can be innovative) will occur only when these methods are in line with employees' values ("innovation-value-fit") (Klein et al., 2001). Engelen et al. (2018) argues that judgments on feasibility and desirability (i.e., the criteria employed for engaging in innovative behaviour) are not fixed but depend on employees' values.

While these arguments call for a fit rationale, employees' values are specified as those related to their national cultural predetermination in this study. National culture refers to enduring personal values that are typically shaped by the time of adolescence (Hofstede, 2001; Ralston et al., 1997; Smircich, 1983). National culture and its values determine employees' interpretation of, understanding of, and behavioural reaction to the work environment, including management practices like corporate support programs. Thus, national culture either facilitates or obstructs corporate support's impact on employees' innovative behaviour (Lachman et al., 1994).

Although economists use culture and institutions distinctively (Engelen et al., 2018; Horak et al., 2018), prior research on innovation consider culture as an integral part of initituions (Klüppel et al., 2018). In the present study, we consider culture as embeded in inistituions, thus the two terms multually effecting each other. Nevertheless, the impact of culture on the link between inistituional pressures and innovative behaviour have not been examined yet. Cultural and societal values influence the way in which employees invlove in developing new ideas an engage in innvoative practices (Engelen et al., 2018). Therefore, firms should pay attention to the sociocultural differences when attempting to develop and carry out innovative practices, as these variances play a crucial role in evaluating of innovative practices (Tata and Prasad, 2015). 
Therefore, the present research examines the impact of the four cultural dimensions of Hofstede on employees' innovative behaviour in the hospitality context. Furthermore, employees' values are determined as those relevant to their national cultural. Prior studies defined national culture as individuals' values that are formed by the time of childhood (e.g., Hofstede, 2001; Ralston et al., 1997). National culture and values play a crucial role in determine employees' ability to understand, interpret, and react to the work climate and management activities such as support programs. Therefore, national culture either promotes or impedes support programs influence on employees' innovative behaviour (Engelen et al., 2018).

Many conceptualizations of national culture were proposed, such as those by Kluckhohn and Strodtbeck (1961), Triandis (1994), Trompenaars and Hampden-Turner (1998), and House, Hanges, Javidan, Dorfman, and Gupta (2004). While each has merits, we use the conceptualization developed by Hofstede (2001) because its validity, reliability, and usefulness have been confirmed over time and in a wide variety of settings (Hofstede, 2001; Kirkman, Lowe, and Gibson, 2006; Li and Parboteeah, 2015; Oyserman, Coon, and Kemmelmeier, 2002; ). It also has an advantage of measuring culture in a relatively large number of countries. While Hofstede's (2001) cultural scores have been widely used, the fact that they are over four decades old and culture changes gradually has raised concerns (Hofstede, 1998). In response, Taras et al. (2012) developed measures of each dimension for each decade from a meta-analysis of studies using Hofstede's measures. To address concerns about using measures from Hofstede's original study (e.g., Hofstede, 1998; Mueller, Rosenbusch, and Bausch, 2013; Steenkamp, 2001), we use updated measures developed from a meta-analysis by Taras, Steel, and Kirkman (2012).

\subsubsection{Individualism-Collectivism}


While the extant literature suggests that collectivistic cultures possess a greater propensity to form 'cooperative ventures' to act to pursue and nurture shared interests, and thus exhibit greater levels of innovation (Park et al., 2007), it also argues that individualistic cultures possess a greater propensity to form voluntary associations with widely dispersed groups as opposed to the culturally enforced and restrictive associations imposed in collectivistic settings, allowing a more favourable innovative behaviour (Husted, 2005). Based on the evidence that stakeholders paying attention to innovation is more widespread in individualistic cultures (Husted, 2005; Katz et al., 2001), we propose that firms in individualistic cultures undertake more innovative initiatives in general. Laws and regulations play an important role in all types of institutional environments. For example, Murtha and Lenway (1994) suggest that government policies on industrial strategies can impose institutionalized pressures on the strategies of multinational firms in various types of institutional environment.

The ties between the individuals could be very loose where everybody is supposed to look after his or her own self-interest and perhaps the interest of immediate family, as is the case in highly individualistic societies. Such societies award the individual a lot of freedom of choice and decision-making and personal initiative in such cases is not only accepted but also encouraged with a high importance being placed on personal goals and achievements. Collectivistic societies, on the other hand, expect its members to look after the benefits of the social group as a whole and conform to the norms of the group. It has been stressed that individual innovativeness would involve an individual who has the natural predisposition towards initiating new behaviour that might be different from the norm. Members of an individualistic society are, thus, more likely to display such behaviour than that of a collectivist society as the latter breeds conformity with the existing norms and accordingly, imitation of expected behaviour.

\subsubsection{Uncertainty Avoidance}


The uncertainty avoidance dimension refers to the extent to which a culture tolerates high levels of uncertainty and ambiguity and therefore risk (Hofstede, 2011). While it has been suggested that firms in contexts involving higher levels of uncertainty avoidance tend to undertake more innovative initiatives (Park et al., 2007), a low uncertainty avoidance context provides organizations with greater empowerment and freedom to focus on social and innovative issues as opposed to being confined to following regulations imposed by bureaucracies (Husted, 2005). Based on the notion that undertaking innovative initiatives involves tolerance of risk and ambiguities, since it may force organizations to challenge the established and proven institutionalized norms as well as dealing with the longer-term period of uncertainty associated with having to wait to realize the return on investments in innovative initiatives, we propose that the latter view that firms in low uncertainty avoidance cultures undertake greater levels of innovative initiatives than firms in high uncertainty avoidance cultures holds greater appeal within the context of the proposed framework. In the presence of external pressures to undertake innovative initiatives, we also propose that uncertainty avoidance will moderate the influence of the various types of external pressure on innovative behaviour .Firms in contexts with a greater preference for uncertainty avoidance (compared with firms in low uncertainty avoidance contexts) will respond more strongly to high levels of coercive and normative isomorphism, since the preference for uncertainty avoidance can compel organizations to rely more heavily on rules, regulations and industry standards to avoid the negative consequences and exposure associated with noncompliance. Firms in high uncertainty avoidance contexts also respond more strongly to mimetic isomorphic pressure, since, as discussed earlier, mimetic isomorphism is strongest in the case of situations involving ambiguity and uncertainty (DiMaggio and Powell, 1983). Thus, weak uncertainty avoidance cultures accept this uncertainty and tend to take each day as it comes, taking risks rather easily, and being more 
tolerant of behaviour and opinions different from their own because they do not feel threatened by them.

\subsubsection{Power distance}

This dimension of culture involves the societal tolerance of unequal distribution of power and autocratic leadership (Hofstede, 2011). Reliance on authority to make important decisions, bureaucracy and a lack of opportunity to challenge assumptions are characteristics of higherpower-distance contexts. We propose that such characteristics restrict firms' ability to undertake debates and challenges associated with focusing on innovative issues; therefore, we suggest that firms in low-power-distance oriented cultures enjoy greater freedom to undertake innovative initiatives than firms in high-power-distance oriented cultures, which may be restricted by the bureaucracy in the environment from engaging in the levels of freedom and exploration required to undertake innovative initiatives. However, since firms face greater pressure to follow rules and regulations in high-power-distance contexts and have a greater incentive to mimic strong and powerful firms (Calori et al., 1997; Hofstede, 2011), we also propose that, when external pressures for innovative behaviour are already present, firms in higher-power-distance contexts tend to respond more strongly to coercive and mimetic pressures, while firms in lower-power-distance contexts may respond more favourably to normative pressure to conform to professional standards or even engage. The dimension of power distance has been found to be inversely related with individualism, that is, low power distance cultures tend to be highly individualistic while large power distance cultures collectivistic.

\subsubsection{Masculinity-Femininity}

While there is empirical evidence on gender differences in innovative behaviour (Zelezny et al., 2000), Hofstede (2011) identifies masculinity with terms such as material success, progress, 
equity, competition and ambition while describing femininity in terms of factors such as nurturing, caring, interpersonal relationships and quality of life. Further, Hofstede sees a direct connection between masculinity and material possessions by arguing that masculine values tend to favour economic advancement over environmental concerns (2011). Similarly, FranzBalsen (2014) argues that conventional 'norms of masculinity are clearly intension with the ethical, ecological and social implications of innovation (...)' (p. 1973). It is believed that a focus on economic growth, by trend rather typical for cultures with pronounced masculine values, often causes a reduced commitment to innovative initiatives; innovative behaviour may be more slowly adapted and existing innovative problems may receive lower priorities (Husted, 2005; Palmer et al., 1995). More masculine societies are expected to place an emphasis on wealth, achievement, success, etc. which might be indirectly reflected in individual's material possessions and the quantity or variety of the possessions. Individuals from such societies would therefore be expected to be more curious of new products in the marketplace which would help them display their achievements. Therefore, our study suggests the following hypotheses:

H3. The positive relationship between institutional pressures (i.e., normative, mimetic, and coercive pressures) and employees' innovative behaviour is stronger when national cultural power distance, collectivism, uncertainty avoidance, and masculinity are low rather than high.

H4. The positive relationship between corporate support programs and employees' innovative behaviour is stronger when national cultural power distance, collectivism, uncertainty avoidance, and masculinity are low rather than high.

\section{Methodology}

\subsection{Sample and data collection}

The current study was carried out with data collected from five nations (UAE, U.K, Germany, China, and USA). Country selection was made based on a number of criteria. First, the authors' 
aim was to analyse the effects of institutional pressures and corporate support programs on innovative behaviour in countries belonging to different cultural clusters - Germanic Europe, Asian, Middle East, and Anglo (see Gupta and Hanges 2004; House, Quigley, and de Luque 2010). As representative of the Anglo cluster, the USA was chosen. As representative of the Middle East cluster, UAE was selected. China was selected as representative of the Asian cluster, and for the Germanic cluster, Germany was included. With regard to the selection of the single countries as representative of the four clusters, we included countries which represent important markets for innovations (USA, Germany, and China). In addition, the US market was considered very important as innovation has a long tradition there (Josifidis and Supic, 2020) and most research on innovations to date has been conducted in the USA. (Aldieri et al., 2019).

Our research used different data sources to cover the study variables. For employees innovative behaviour and corporate support programs, our study used the 2018 Global Entrepreneurship Monitor (GEM), which includes data on entrepreneurial innovative employee behaviour in different nations (Bosma et al., 2013; Reynolds et al., 2005). Our study integrate the GEM data with Taras et al.'s (2012) national culture scores on Hofstede's dimensions, leading to complete datasets of 2,618 respondents from a broad set of five economically and culturally different societies (UK, UAE, Germany, China, USA). Table 1 demonstrates the nation scores about the national cultural dimensions.

Regarding the institutional pressures (i.e., coercive, mimetic, and normative), the data came from an online survey sent to a sample of employees who are representative of the hotels industry during March-April 2019. The study population involved the workers who were employed at deluxe (five-star) hotels, such as the Marriott, Sofitel, Hilton, Novotel, InterContinental, Ritz-Carlton, and Lotte. These hotels include more than 200 rooms that provide guests with different services, such as restaurants and fitness centers. Once the 
permission from the HR manager has been given, we provide employees with the survey and were asked to complete the self-administered questionnaires. The present study employs quota sampling and 500 questionnaires and return envelopes were provided to employees from five different society (UK, UAE, Germany, China, and USA). Excluding non-response resulting in complete datasets of 1,794 employees (response rate 1,794/2,500 $=71.8 \%$ ). A questionnaire was designed to measure the variables of interest. Following a back-to-back translation method, two bilingual researchers first designed the questionnaire in English and then translated it to Arabic, German, and Chinese. A pilot test was undertaken with 20 respondents from the UAE.

\subsection{Measures}

Employees' innovative behaviour: The measure for employees' innovative behaviour is based on the 2018 GEM special report and defined as a binary variable, where 1 indicates that the surveyed employee is currently or has been within the previous three years actively involved in developing new activities for his or her main employer, and zero otherwise (Bosma et al., 2013). New activities are defined in the questionnaire as activities related to the initiation of new products or services. Single-item dichotomous scales are almost exclusively used in GEM projects since these scales have minimal bias that can be due to cultural interpretations (Autio et al., 2013; Engelen et al., 2018). In addition, dichotomous scales have few problems with translation equivalence (Hofstede, Wedel, and Steenkamp, 2002; Romero and MartínezRomán, 2012).

Corporate support: a binary variable- attaining a value of 1 if the employer is willing to provide support when employee creates and develops new ideas for new services or products, and 0 otherwise (Bosma et al., 2013; Engelen et al., 2018). This variable is also based on the 2018 GEM report. 
National culture: our study conceptualized national culture using the four national cultural dimensions of individualism, uncertainty avoidance, masculinity, and power distance (Engelen et al., 2018; Minkov and Hofstede, 2012). Our study used the scores from Taras et al. (2012).

Institutional pressures (i.e., normative, mimetic, and coercive): The present study used scales validated in the literature, to guarantee the validity and reliability of our research measurements. In particular, institutional pressures were measured through 3 dimensions (e.g., Colwell and Joshi, 2013; Dubey et al., 2017; Gualandris and Kalchschmidt, 2014; Zhu and Sarkis, 2007): normative (3 items), mimetic (4 items), and coercive (3 items). All indicators were measured with 10 items using a 5-point scale.

Our analysis include responses from 2,360 full-time employees in five different society (UK, UAE, Germany, China, and USA). Of the 2,360 employees, 480 (19\%) employees from UK, 495 (14\%) from UAE, 376 (13\%) from German, 351 (17\%) from China, and 658 (16\%) from the USA. The mean age of the employees was 34.28 years and $52.6 \%$ were between 30 and 39 years of age. The employees were $56.4 \%$ male and $43.6 \%$ female. Most had a university degree $(68.6 \%)$ and $69.8 \%$ had been with a deluxe hotel for less than 10 years. The majority of them were ordinary employees $(43.7 \%)$.

\section{Data Analysis and Results}

Table 2 presents descriptive statistics (i.e., mean, maximum, minimum, and standard deviation) and correlations about the research factors. Our data shows low correlations among the independents variables and the value of VIF is low, indicating that there were no issues on collinearity between the factors and thus validating the efficiency of the estimation (Wooldridge, 2012). 
The present study analysed and structured the data as a hierarchical dataset gathered by country, utilising a multilevel study approach in which individual (level 1) are overlapped within nations (level 2). Since our study has dummy variables (i.e., innovative behaviour and corporate support programs), a logit model was estimated. The present study utilised a multilevel mixed-effects method to model binary factors in which the log odds of the dependent factors were modelled as linear sets of the independent factors (Agresti, 2013; Engelen et al., 2018).

The present study applied several analyses: Based on Rabe-Hesketh and Skrondal (2008), our study conducted the $X^{2}$ test to show a low and high significant p-value; Akaike's information criterion (AIC) was conducted and it demonstrated an improvement in model fit when the national culture and the main effect were incorporated (Akaike, 1998); according to Menard (2002), our study conducted the likelihood ratio test versus the logistic regression and the findings confirmed that a multilevel research approach is most suitable for the data; the interaction models were compared with the nested model 3 by conducting a pairwise likelihood ratio analysis and the findings suggest that the national culture can improve our model fit partially.

Table 3 indicates the findings of the log odds regression. Table 4 demonstrates the odds ratios to indicate the effects size, reveal the change in the strength of the dependent factor (i.e., innovative behaviour) that comes from a the independent factors changes (i.e., institutional pressures and corporate support programs). When odds ratio value is 1.00 , means there is no associations between independent and dependent factors, while an odds ratios lower 1.00 shows negative links between independent and dependent factors, and odds ratios greater than 1.00 demonstrates positive associations between the independent and dependent factors (Hillman et al., 2007). 
Table 3 indicates the values of the pseudo R-square according to the formula from McFadden (Hoetker, 2007). Prior studies indicated that Multilevel approach is used when intra-class correlations demonstrate significant variances at the individual level. Our study results demonstrate a mong country difference of $14 \%$, suggesting the adoption of multilevel methods over OLS approach.

Model 1 investigates the influence of control variables (i.e., individual and country level). The results indicate that the individual-level factors had a significant influence on innovative behaviour, while GDP has no influence on innovative behaviour. Model 2 which includes the main influence for institutional pressures and corporate support programs. The results revealed that institutional pressures have significant influence on innovative behaviour $(\beta=1.663$, $\mathrm{p}<0.001$ ), indicating that institutional pressures increase employees' innovative behaviour, demonstrating that an increase of one standard deviation in institutional pressures increases the influence of institutional pressures on employees' innovative behaviour by $373 \%$ (odds ratios 4.7). These results support H1. Furthermore, The results indicated that corporate support programs had a significant influence on innovative behaviour $(\beta=1.892, \mathrm{p}<0.001)$, indicating that corporate support programs enhance employees' innovative behaviour, demonstrating that an improve of one standard deviation in support programs improves the influence of support programs on employees' innovative behaviour by $421 \%$ (odds ratios 5.2 ). These results support $\mathrm{H} 2$.

Model 3 incorporates the country scores, and models 4, 5, 6, and 7 include the interaction effects. Model 4 demonstrates a positive association between the interaction effects for institutional pressures and individualism and innovative behaviour $(\beta=0.379, \mathrm{p}<0.001)$. The value of the odds ratio is 0.849 demonstrates that an increase of one standard deviation in a country's individualism increases the influence of institutional pressures on employees' innovation behaviour by $15.1 \%$. The findings also show a positive link between the interaction 
effects for corporate support programs and individualism and innovative behaviour $(\beta=0.620$, $\mathrm{p}<0.001)$. The value of the odds ratio is 0.830 demonstrates that an improve of one standard deviation in a country's individualism improves the influence of support programs on employees' innovation behaviour by $17 \%$.

Model 5 reveals a negative moderating influence of power distance on the link among institutional pressures and employees' innovative behaviour $(\beta=-0.285, \mathrm{p}<0.001)$. The value of the odds ratio is 0.816 demonstrates that an improve of one standard deviation in a country's power distance reduces the influence of institutional pressures on employees' innovation behaviour by $18.4 \%$. The findings also show a negative link among the interaction effects for support programs and power distance and innovative behaviour $(\beta=-0.399, \mathrm{p}<0.001)$. The value of the odds ratio is 0.774 demonstrates that an improve of one standard deviation in a country's power distance reduces the influence of support programs on employees' innovation behaviour by $22.6 \%$.

Model 6 shows a significant negative moderating influence of uncertainty avoidance on the link among institutional pressures and employees' innovative behaviour $(\beta=-0.417, \mathrm{p}<0.001)$. The value of the odds ratio is 0.903 demonstrates that an improve of one standard deviation in a country's uncertainty avoidance reduces the influence of institutional pressures on employees' innovation behaviour by $9.9 \%$. The findings also show a negative link among the interaction effects for support programs and uncertainty avoidance and innovative behaviour $(\beta=-0.491, \mathrm{p}<0.001)$. The value of the odds ratio is 0.851 demonstrates that an improve of one standard deviation in a country's uncertainty avoidance reduces the influence of support programs on employees' innovation behaviour by $14.9 \%$.

Model 7 demonstrates a significant negative influence of masculinity on the link among institutional pressures and employees' innovative behaviour $(\beta=-0.629, \mathrm{p}<0.001)$. The value of the odds ratio is 0.716 demonstrates that an increase of one standard deviation in a country's 
masculinity decreases the influence of institutional pressures on employees' innovation behaviour by $28.4 \%$. The findings also show a negative link between the interaction effects for support programs and masculinity and innovative behaviour $(\beta=-0.614, \mathrm{p}<0.001)$. The value of the odds ratio is 0.907 demonstrates that an improve of one standard deviation in a country's masculinity reduces the influence of support programs on employees' innovation behaviour by 9.3\%. The results indicated in Tables 6 and 7 support $\mathrm{H} 3$ and $\mathrm{H} 4$.

Robustness analyses. Our study conducted a subsample sensitivity method that revealed consistent findings. U.K. accounts for $31 \%$ of the sample size and is the highest country in the dataset, however excluding U.K. from our analysis does not change the directions of levels of the coefficients. The present study tested for outliers in the control factors and revealed a low prevalence of the factor "income" in Germany. Excluding Germany from our data did not change the directions of the coefficient. The moderation influences increase from $15 \%$ to $10 \%$ (individualism) or decrease from $15 \%$ to $20 \%$ (masculinity).

\section{Discussion and Conclusions}

\subsection{Conclusions}

Academic studies recently suggested that studies on innovative behaviour should move outside of single-country research and consider national variances in innovation in the tourism and hospitality context (Engelen et al., 2018; Gu, Duverger, and Yu, 2017; Romero et al., 2012). Our study was acted on these suggestions and investigated cross national variances in employees' innovative behaviour using institutional theory and fit theory. Our study aims to develop theoretically and validate that institutional pressures and support programs can improve employees' innovative behaviour in the hospitality industry. Our study suggests a significant relationship between institutional pressures, support programs, and innovative 
behaviour in these countries. Furthermore, national culture factors have been examined to understand the influence of cross-country differences on these relationships. Our study revealed that corporate support programs and institutional pressures facilitates employees' innovative behaviour, particularly in the low power distance and individualistic cultures.

Our results revealed that national culture determines the link between institutional pressures, support programs and innovative behaviour. These findings are consistent with fit theory, which affirms the notion that developing innovative behaviour is a complex function and national culture plays a crucial role in the managers ability to develop corporate support programs to foster employees innovative behaviour. Therefore, our finding confirms that the employees innovative behaviour from different countries can be explained, to some extent, by fit theory. Our findings are also in line with prior research in the cross-cultural context, which found that culture influences on employees innovative behaviour (Engelen et al., 2018; Hohenberg and Homburg, 2016).

In the Western context, we consistently find that there is a positive relationship between corporate support programs and innovative employee behavior

Our findings provided evidence for the positive relationship between institutional pressures (i.e., normative, mimetic, and coercive) and employees innovative behaviour in the full sample of countries, developed and developing countries in the hospitality industry. These results are consistent with prior studies results (e.g., Colwell and Joshi, 2013; Dhar, 2016; Dubey et al., 2017; Gualandris and Kalchschmidt, 2014; Jung and Yoon, 2018) who found that institutional pressures play a critical role in enhancing employees innovative behaviour.

\subsection{Theoretical implications}

Our study offers several theoretical contributions for the literature on innovative behaviour in the hospitality context. First, our study incorporates a fit theory view to the study area of 
innovation. The findings of the present study revealed that drivers' ability to influence innovative behaviour vary across societies. The logic of the fit theory is that employees' expectations and needs of their company and their company's practices vary according to the values and preferences of the employees. Therefore, innovative behaviour needs a deep investigation of how the preferences and needs of employees are rooted in their cultures before suggestions for carrying out specific antecedents of innovative behaviour can be made.

Second, our study contributes empirically and theoretically to studies on innovation and national culture. Prior research revealed that national culture are understudied in the context of innovation (Eisend et al., 2016). Anderson et al. (2014) indicate the need for research on the innovation across national, as "theorizing and research in this regard have lagged behind practical needs" (p. 1301). Martín-Rios and Ciobanu (2019) indicated the lack of empirical cross-national research in the context of innovation in the tourism and hospitality industry. Our study addressing this gap by developing theoretically and validate empirically that employees' innovative behaviour is influenced by the interaction of national culture, institutional pressures, and corporate support programs in the hospitality context. Furthermore, prior studies indicated that most of the studies on innovative behaviour have been performed in the developed context (Stock, 2015). To the best of our knowledge, our study is the first to examine the influence of institutional pressures and corporate support programs on innovative behaviour across national. Third, our research offers contributions to employees innovative behaviour by developing and empirically validating a multilevel model of the link between institutional pressures, corporate support, and employees innovative behaviour. Prior studies revealed that multilevel models are lacking in innovation studies (Anderson et al., 2014). By incorporating firm and nation level factors into this research, our research reacts to Hitt et al. (2007) call to develop models with factors on firm and nation levels to address the complexity of employee behaviour in companies. Due to the complexity of this type of behaviour and many impediments to the 
behaviour, using the multilevel view can address the interaction between antecedents at the firm and national level in driving innovative behaviour.

\subsection{Practical implications}

Our study responds to the question that always raises by managers concerning whether a particular technique has to be adapted to the local context or has to be standardized global. Global standardization is recommendable (e.g., in terms of simplicity and synergies) and is often reasonable, specifically with regard to techniques of production such as the Toyota Management Program (Spear, 2004). Nevertheless, our study results revealed that similar global standardization of institutional pressures and support programs doesn't cause the required consequences across the nations. Alternatively, the influence of institutional pressures and support programs on innovative behaviour unfolds most strongly in a culture that is high in individualism, and low power distance, uncertainty avoidance, and masculinity. While, the influence of institutional pressures and corporate support programs on employees' innovative behaviour is weaker in a culture that is high in power distance, uncertainty avoidance, and masculinity.

Our study revealed that support programs (i.e., budget, time, and advice) play a crucial role in improving employees' innovative behaviour in a culture that is high in individualism, and low uncertainty avoidance, power distance, and masculinity. Managers should provide their employees' with sufficient budget in order to enable them to create and develop new innovative ideas. For instance, hotels can form a committee where employees who develop innovative ideas can apply for specific budgets. Our study revealed that similar worldwide standardization of corporate support programs for innovation does not lead to the desired outcomes across the globe. Instead, the impact of these programs on innovative employee behaviour unfolds most strongly in national cultural contexts with low levels of power distance, high levels of 
individualism, and low masculinity, characteristics that apply primarily to Western nations (e.g., Germany). When power distance, collectivism, masculinity are strong, corporate support programs might lead to confusion and discomfort, rather than to innovative behaviour. Furthermore, managers should provide their employees with sufficient environmental support. For instance, hotels can create special room within the hotel where employees can go to be inspired. This room can include magazines, pictures of different stimuli, books, and facilities for relaxing that can motivate them to create new ideas and innovative efforts. One way to provide budget is to install a committee to which employees can apply for budgets for building prototypes, market research, or other investments necessary to developing an innovative idea.

Hotels that want to provide time should provide their employees with sufficient time to develop new ideas. For example, managers could provide employees with devoted time for innovative efforts and decreasing main duties appropriately. Moreover, hotels can provide their employees with advices by training managers that employees represent the source of hotel innovation and they might confront some impediments for being innovative so it is managers' duty to show interest, communicate, and give advice to their employees.

Managers should bear in their mind that there are various approach to design their strategies, depending on the external pressures they decided to respond to. Hotels should adopt a certified standard to comply with the consumers expectations and legal provisions. Hernández-Perlines et al (2019) revealed that hotels with ISO 9001 are more likely to promote innovations in their services. Other studies have also established that the positive results of certification are considerable in pioneering companies (Assaker, O'Connor, and El-Haddad, 2020; Corredor and Goöi, 2011). This circumstance occurs because the introduction of quality certification forces hotels to make a significant investment in innovations that generally translates into improved efficiency. 
Our study findings offers important implications for international marketers who want to target different markets. The present study indicates that institutional pressures (i.e., mimetic, normative, and coercive) can impose external pressures on multinational companies in different types of environment. Therefore, hotels in cultures with high levels of uncertainty avoidance, collectivism, power distance, and masculinity (e.g., UAE and China) will indicate greater levels of innovative behaviour in response to normative, mimetic, and coercive pressure than hotels in cultures with low levels of collectivism, power distance, uncertainty avoidance, and masculinity (e.g., U.K., Germany, and USA).

\subsection{Limitations and directions for future research}

Although the present research makes some contributions, it also has a number of limitations, which at the same time give opportunities for further studies. First, since this research has been conducted within hotels context, there may have been some limitation on the range of some measures so the generalizability of results should be tested in different environments. Second, Although a number of variables were investigated in this research, future research can include different aspects of the work environment such as pressures, organizational barriers to creativity, resources, and peer/ supervisor support (Birdi et al., 2016; Cokpekin and Knudsen, 2012; Rahim, 2014), as well as the demographic factors of employees. Finally, our study used self-reported data in order to measure institutional pressures variables (i.e., normative, mimetic, and coercive). This method was widely used in previous studies, however, utilising other data sources could enhance the reliability and validity of these variables. 


\section{References}

Adebanjo, D., Teh, P.L., Ahmed, P.K., 2018. The impact of supply chain relationships and integration on innovative capabilities and manufacturing performance: the perspective of rapidly developing countries. International journal of production research, 56(4),17081721.

Afsar, B., Badir, Y., 2017. Workplace spirituality, perceived organizational support and innovative work behavior: The mediating effects of person-organization fit. Journal of workplace Learning. 29(2), 95-109.

Agresti, A., 2013. Categorical data analysis. Hoboken, NJ: John Wiley \& Sons.

Ahmadi, H.B., Kusi-Sarpong, S., Rezaei, J., 2017. Assessing the social sustainability of supply chains using Best Worst Method. Resources, Conservation and Recycling. 126, 99-106.

Aldebert, B., Dang, R.J., Longhi, C., 2011. Innovation in the tourism industry: The case of Tourism. Tourism management. 32(5), 1204-1213.

Aldieri, L., Carlucci, F., Cirà, A., Ioppolo, G., Vinci, C.P., 2019. Is green innovation an opportunity or a threat to employment? An empirical analysis of three main industrialized areas: The USA, Japan and Europe. Journal of Cleaner Production, 214(2), 758-766.

Amarakoon, U., Weerawardena, J., Verreynne, M.L., 2018. Learning capabilities, human resource management innovation and competitive advantage. The International Journal of Human Resource Management. 29(10), 1736-1766.

Anderson, N., K. Potoc`nik, J. Zhou., 2014. Innovation and creativity in organizations: A stateof-the-science review, prospective commentary, and guiding framework. Journal of Management. 40 (5): 1297-333.

Anning-Dorson, T., 2018. Innovation and competitive advantage creation: The role of organisational leadership in service firms from emerging markets. International Marketing Review. 35(4), 580-600.

Assaker, G., O'Connor, P. and El-Haddad, R., 2020. Examining an integrated model of green image, perceived quality, satisfaction, trust, and loyalty in upscale hotels. Journal of Hospitality Marketing \& Management, 23(2),11-22.

Bammens, Y. P., 2016. Employees' innovative behavior in social context: A closer examination of the role of organizational care. Journal of Product Innovation Management. 33 (3): 244-59.

Bani-Melhem, S., Zeffane, R., Albaity, M., 2018. Determinants of employees' innovative behavior. International Journal of Contemporary Hospitality Management. 30(3), 16011620.

Berrone, P., A. Fosfuri, L. Gelabert, L. R. Gomez-Mejia., 2013. Necessity as the Mother of 'Green' inventions: Institutional Pressures and Environmental Innovations. Strategic Management Journal, 34 (8), 891-909.

Binder, P., Mair, M., Stummer, K., Kessler, A., 2016. Organizational innovativeness and its results: a qualitative analysis of SME hotels in Vienna. Journal of Hospitality \& Tourism Research, 40(3), 339-363.

Birdi, K., Leach, D., Magadley, W., 2016. The relationship of individual capabilities and 
environmental support with different facets of designers' innovative behavior. Journal of Product Innovation Management. 33(1),19-35.

Bohnsack, R., Kolk, A., Pinkse, J., Bidmon, C.M., 2020. Driving the electric bandwagon: The dynamics of incumbents' sustainable innovation. Business Strategy and the Environment, 29(2), 727-743.

Bosma, N., Wennekers, S., Guerrero, M., Amorós, J. E., Martiarena, A., Singer, S., 2013. Global Entrepreneurship Monitor: Special report on entrepreneurial employee activity.: GERA.

Brem, A., Maier, M., Wimschneider, C., 2016. Competitive advantage through innovation: the case of Nespresso. European Journal of Innovation Management. 19(1), 133-148.

By, R.T., Dale, C., 2008. The successful management of organisational change in tourism SMEs: initial findings in UK visitor attractions. International journal of tourism research. 10(4), 305-313.

Cajaiba-Santana, G., Faury, O., Ramadan, M., 2020. The emerging cruise shipping industry in the arctic: Institutional pressures and institutional voids. Annals of Tourism Research. 80, 102-179.

Calori, R., Lubatkin, M., Very, P., Veiga, J., 1997. Modelling the origins of nationally-bound administrative heritages: a historical institutional analysis of French and British firms. Organization Science. 8(6): 681-696.

Camisón, C., Monfort-Mir, V.M., 2012. Measuring innovation in tourism from the Schumpeterian and the dynamic-capabilities perspectives. Tourism management. 33(4), 776-789.

Cao, L., Li, L., 2018. Determinants of Retailers' Cross-channel Integration: An Innovation Diffusion Perspective on Omni-channel Retailing. Journal of Interactive Marketing. 44,1-16.

Cheffi, W., Abdennadher, S., 2019. Executives' Behaviour and Innovation in Corporate Governance: The Case of Internet Voting at Shareholders' General Meetings in French Listed Companies. Journal of Business Ethics. 156(3),775-798.

Chen, Y.S., Lin, M.J.J., Chang, C.H., 2009. The positive effects of relationship learning and absorptive capacity on innovation performance and competitive advantage in industrial markets. Industrial Marketing Management. 38(2), 152-158.

Chou, Shih Yung., Brandon Walker-Price., 2018. Fostering employee innovative behaviour through receipt of helping and voice behaviours from co-workers: the mediating roles of knowledge transfer and knowledge creation. International Journal of Entrepreneurship and Innovation Management. 22(4-5), 451-470.

Cobos, L.M., Mejia, C., Ozturk, A.B., Wang, Y., 2016. A technology adoption and implementation process in an independent hotel chain. International Journal of Hospitality Management, 57(1), 93-105.

Cokpekin, Ö., M. P. Knudsen., 2012. Does organizing for creativity really lead to innovation? Creativity and Innovation Management. 21: 304-14.

Colwell, S. R., Joshi, A. W., 2013. Corporate ecological responsiveness: Antecedent effects of institutional pressure and top management commitment and their impact on organizational 
performance. Business Strategy and the Environment. 22(2), 73-91.

Conroy, S., Henle, C.A., Shore, L., Stelman, S., 2017. Where there is light, there is dark: A review of the detrimental outcomes of high organizational identification. Journal of organizational behavior, 38(2), 184-203.

Currie, W.L., 2012. Institutional isomorphism and change: the national programme for IT-10 years on. Journal of Information Technology. 27(3), 236-248.

Damanpour, F., 2014. Footnotes to Research on Management Innovation. Organization Studies, 36 (9), 1265-1285.

Damanpour, F., Aravind, D., 2011. Managerial innovation: Conceptions, processes, and antecedents. Management and Organisation Review. 8, 423-454.

De la Pena, M.R., Nunez-Serrano, J.A., Turrion, J. and Velázquez, F.J., 2016. Are innovations relevant for consumers in the hospitality industry? A hedonic approach for Cuban hotels. Tourism Management, 55, pp.184-196.

De Leeuw, T., Gössling, T., 2016. Theorizing change revisited: An amended process model of institutional innovations and changes in institutional fields. Journal of Cleaner Production. 135, 435-448.

Dhar, R. L., 2016. Ethical leadership and its impact on service innovative behavior: The role of LMX and job autonomy. Tourism Management. 57(7), 139-148.

Dhar, R.L., 2015. The effects of high performance human resource practices on service innovative behaviour. International Journal of Hospitality Management. 51, 67-75.

DiMaggio, P. J., W. W. Powell. 1983. The Iron Cage Revisited: Institutional Isomorphism and Collective Rationality in Organizational Fields. American Sociological Review 48 (2), 147-160.

DiMaggio, P.J., Powell, W.W., 1983. The iron cage revisited: Institutional isomorphism and collective rationality in organizational fields. American sociological review. 34(8),147160.

Domínguez-Escrig, E., Mallén-Broch, F.F., Lapiedra-Alcamí, R., Chiva-Gómez, R., 2019. The influence of leaders' stewardship behavior on innovation success: the mediating effect of radical innovation. Journal of Business Ethics. 159(3), 849-862.

Dos Santos, M.G., Borini, F.M., Pereira, R.M., Raziq, M.M., 2020. Institutional pressures and the diffusion of organisational innovation: evidence from Brazilian firms. Technology Analysis \& Strategic Management, pp.1-12.

Dubey, R., Gunasekaran, A., Childe, S.J., Papadopoulos, T., Hazen, B.T., Roubaud, D., 2017. Examining top management commitment to TQM diffusion using institutional and upper echelon theories. International Journal of Production Research. 56(8), 2988-3006.

Dubey, R., Gunasekaran, A., Childe, S.J., Papadopoulos, T., Helo, P., 2019. Supplier relationship management for circular economy: influence of external pressures and top management commitment. Management Decision. 57(4),767-790.

Dusana, H., Paul, T., Don, S. C., 2016. Uncovering the reciprocal complementarity between product and process innovation. Research Policy. 45, 929-940.

Edghiem, F., Mouzughi, Y., 2018. Knowledge-advanced innovative behaviour: a hospitality 
service perspective. International Journal of Contemporary Hospitality Management. 30(1),197-216.

Eisend, M., H. Evanschitzky, D. I., Gilliland., 2016. The influence of organizational and national culture on new product performance. Journal of Product Innovation Management 33 (3): 260-76.

Ekvall, G., L. Ryhammar., 1999. The creative climate: its determinants and effects at a Swedish university. Creativity Research Journal. 12 (4): 303-10.

Engelen, A.,Weinekotter, L., Saeed, S., Enke, S., 2018. The effect of corporate support programs on employees' innovative behavior : a cross-cultural study. Journal of product innovation management. 35 (2). 230-253.

Farh, J.-L., D. Hackett, J., Liang., 2007. Individual-level cultural values as moderators of perceived organizational support employee outcome relationships in China: Comparing the effects of power distance and traditionality. Academy of Management Journal.50 (3): 715-29.

Franz-Balsen, A., 2014. Gender and (un) sustainability - can communication solve a conflict of norms? Sustainability. 6(4): 1973-1991.

Fuentelsaz, L., Gómez, J., Palomas, S., 2016. Interdependences in the intrafirm diffusion of technological innovations: Confronting the rational and social accounts of diffusion. Research Policy. 45(5), 951-963.

Fuentelsaz, L., Maicas, J.P., Montero, J., 2018. Entrepreneurs and innovation: The contingent role of institutional factors. International Small Business Journal. 36(6), 686-711.

Galende, J., de la Fuente, J.M., 2003. Internal factors determining a firm's innovative behaviour. Research Policy. 32(5),715-736.

Garud, R., Hardy, C., Maguire, S., 2007. Institutional entrepreneurship as embedded agency: An introduction to the special issue. 957-969.

Geels, F.W., 2004. From sectoral systems of innovation to socio-technical systems: Insights about dynamics and change from sociology and institutional theory. Research policy, 33(6-7), 897-920.

Gollwitzer, P., 1996. The volitional benefits of planning. In The psychology of action: Linking cognition and motivation to behavior, ed. P. Gollwitzer and J. Bargh, 287-312. New York: Guilford Press.

Greenwood, R., Hinings, C.R., 1996. Understanding radical organizational change: Bringing together the old and the new institutionalism. Academy of management review. 21(4), 1022-1054.

Gu, H., Duverger, P., Yu, L., 2017. Can innovative behavior be led by management? A study from the lodging business. Tourism Management, 63(3), 144-157.

Guo, L., 2008. An analysis of 22 years of research in JPIM. Journal of Product Innovation Management. 25 (3): 249-60.

Gupta, V., P.J. Hanges., 2004. Regional and climate clustering of societal cultures. In

Culture, leadership and organizations: The GLOBE study of 62 societies, ed. R.J. House, P.J.. 
Hambrick, D.C., 2007. Upper echelons theory: An update.

Hansen, J.A., Pihl-Thingvad, S., 2019. Managing employee innovative behaviour through transformational and transactional leadership styles. Public Management Review. 21(6), 918-944.

Hernández-Perlines, F., Ariza-Montes, A., Han, H. and Law, R., 2019. Innovative capacity, quality certification and performance in the hotel sector. International Journal of Hospitality Management, 82, pp.220-230.

Herrera, M.E.B., 2015. Creating competitive advantage by institutionalizing corporate social innovation. Journal of Business Research. 68(7),1468-1474.

Hillman, A. J., C. Shropshire, A. A., Cannella., 2007. Organizational predictors of women on corporate boards. Academy of Management Journal. 50 (4): 941-52.

Hitt, M. A., W. Beamish, S. E. Jackson, J. E. Mathieu., 2007. Building theoretical and empirical bridges across levels. multilevel research in management. Academy of Management Journal. 50 (6): 1385-99.

Hoetker, G., 2007. The use of logit and probit models in strategic management research: Critical issues. Strategic Management Journal. 28 (4): 331-43.

Hofstede G., 2001. Culture's Consenquences. Comparing Values, Behaviors, Institutions, and Organizations Across Nations, 2nd edition. Thousand Oaks, CA: Sage.

Hofstede, G., 2001. Culture's consequences: Comparing values, behaviors, institutions, and organizations across nations (2nd ed.). Thousand Oaks, CA: Sage

Hofstede, G., 2011. Dimensionalizing cultures: the Hofstede model in context. Online Readings in Psychology and Culture. 2(1): 1-26.

Hohenberg, S., C. Homburg., 2016. Motivating sales reps for innovation selling in different cultures. Journal of Marketing. 80 (2): 101-20.

Horak, S., Arya, B., Ismail, K.M., 2018. Organizational sustainability determinants in different cultural settings: A conceptual framework. Business Strategy and the Environment. 27(4), 528-546.

House, R. J., Hanges, P. J., Javidan, M., Dorfman, P. W., \& Gupta, V. (Eds.)., 2004. Culture, leadership, and organizations: The GLOBE study of 62 societies. Thousand Oaks, CA: Sage.

House, R.J., N.R. Quigley, M.S. de Luque., 2010. Insights from project GLOBE. International Journal of Advertising 29(1), 119-39.

Hsiao, T.Y., Chuang, C.M., Huang, L., 2018. The contents, determinants, and strategic procedure for implementing suitable green activities in star hotels. International Journal of Hospitality Management, 69(4), 1-13.

Huang, S.S., Crotts, J., 2019. Relationships between Hofstede's cultural dimensions and tourist satisfaction: A cross-country cross-sample examination. Tourism management, 72(7), 232-241.

Husted, B., 2005. Culture and ecology: a cross-national study of the determinants of environmental sustainability. Management International Review. 45(3): 349-371. 
Ireland, R.D., Webb, J.W., 2007. Strategic entrepreneurship: Creating competitive advantage through streams of innovation. Business horizons. 50(1), 49-59.

Josifidis, K., Supic, N., 2020. Innovation and Income Inequality in the USA: Ceremonial versus Institutional Changes. Journal of Economic Issues, 54(2), 486-494.

Kale, E., Aknar, A., Başar, Ö., 2019. Absorptive capacity and firm performance: The mediating role of strategic agility. International Journal of Hospitality Management. 78, 276-283.

Kasperavičiūtė-Černiauskienė, R., D. Serafinas., 2018. The Adoption of ISO 9001 Standard Within Higher Education Institutions in Lithuania: Innovation Diffusion Approach.Total Quality Management \& Business Excellence, 29 (1-2), 74-9.

Katz, JP., Swanson, DL., Nelson, LK., 2001. Culture-based expectations of corporate citizenship: a propositional framework and comparison of four cultures. International Journal of Organizational Analysis. 9(2): 149-172.

Kauppi, K., 2013. Extending the Use of Institutional Theory in Operations and Supply Chain Management Research: Review and Research Suggestions. International Journal of Operations \& Production Management. 33 (10): 1318-1345.

Kiefhaber, E., Pavlovich, K., Spraul, K., 2020. Sustainability-Related Identities and the Institutional Environment: The Case of New Zealand Owner-Managers of Small-and Medium-Sized Hospitality Businesses. Journal of Business Ethics, 163(1), 37-51.

Kimberly, J.R., Evanisko, M.J., 1981. Organizational innovation: The influence of individual, organizational, and contextual factors on hospital adoption of technological and administrative innovations. Academy of management journal. 24(4), 689-713.

Kirkman, B. L., Lowe, K. B., Gibson, C. B., 2006. A quarter century of Culture's Consequences: A review of empirical research incorporating Hofstede's cultural values framework. Journal of International Business Studies, 37(1), 285-320.

Kluckhohn, F. R., Strodtbeck, F. L., 1961. Variations in value orientations. Evanston, IL: Row, Peterson.

Klüppel, L.M., Pierce, L., Snyder, J.A., 2018. Perspective-The deep historical roots of organization and strategy: traumatic shocks, culture, and institutions. Organization Science. 29(4), 702-721.

Lam, C., Law, R., 2019. Readiness of upscale and luxury-branded hotels for digital transformation. International Journal of Hospitality Management. 79(3), 60-69.

Lau, P.Y.Y., McLean, G.N., Hsu, Y.C., Lien, B.Y.H., 2017. Learning organization, organizational culture, and affective commitment in Malaysia: A person-organization fit theory. Human Resource Development International, 20(2),159-179.

Laukkanen, M., Patala, S., 2014. Analysing barriers to sustainable business model innovations: Innovation systems approach. International Journal of Innovation Management. 18(06), 1440010 .

Le, P. B., Lei, H., 2019. Determinants of innovation capability: the roles of transformational leadership, knowledge sharing and perceived organizational support. Journal of Knowledge Management. 23(3), 527-547.

Lee, D.Y., Dawes, P.L., 2005. Guanxi, trust, and long-term orientation in Chinese business 
markets. Journal of international marketing.13(2), 28-56.

Lengnick-Hall, C.A., 1992. Innovation and competitive advantage: What we know and what we need to learn. Journal of management.18(2), 399-429.

Lewis, A.C., Cardy, R.L., Huang, L.S., 2019. Institutional theory and HRM: A new look. Human Resource Management Review. 29(3), 316-335.

Li, C., Parboteeah, K. P., 2015. The effect of culture on the responsiveness of firms to mimetic forces: Imitative foreign joint venture entries into China 1985-2003. Journal of World Business, 50 (7), 465-476.

Li, M., Hsu, C.H., 2018. Customer participation in services and employee innovative behavior: The mediating role of interpersonal trust. International Journal of Contemporary Hospitality Management. 30(4), 2112-2131.

Liang, H., N. Saraf, Q. Hu., Y. Xue., 2007. Assimilation of Enterprise Systems: The Effect of Institutional Pressures and the Mediating Role of Top Management. MIS Quarterly. 31 (1): 59-87

Liao, Z., 2018. Institutional Pressure, Knowledge Acquisition and a Firm's Environmental Innovation. Business Strategy and the Environment, 27(2), 849-857.

Long, T.B., Blok, V., Coninx, I., 2016. Barriers to the adoption and diffusion of technological innovations for climate-smart agriculture in Europe: evidence from the Netherlands, France, Switzerland and Italy. Journal of Cleaner Production. 112, 9-21.

Lytle, A., J. Brett, Z. Barsness, C. Tinsley, M. Janssens., 1995. A paradigm for confirmatory cross-cultural research in organizational behavior. Research in Organizational Behavior. 17: $167-214$

Mair, J., G. Reischauer., 2017. Capturing the Dynamics of the Sharing Economy: Institutional Research on the Plural Forms and Practices of Sharing Economy Organizations." Technological Forecasting and Social Change 125(3), 11-20.

Markman, G. D., R. A. Baron., 2003. Person-entrepreneurship fit: Why some people are more successful as entrepreneurs than others. Human Resource Management Review. 13 (2): 281.

Martín-Rios, C., Ciobanu, T., 2019. Hospitality innovation strategies: An analysis of success factors and challenges. Tourism Management, 70(2), 218-229.

Massidda, C., Etzo, I., Piras, R., 2017. The relationship between immigration and tourism firms. Tourism Economics. 23(8),1537-1552.

Mazanec, J.A., Crotts, J.C., Gursoy, D., Lu, L., 2015. Homogeneity versus heterogeneity of cultural values: An item-response theoretical approach applying Hofstede's cultural dimensions in a single nation. Tourism Management, 48(1), 299-304.

Menard, S. W., 2002. Applied logistic regression analysis (2nd ed.). Thousand Oaks, CA: Sage Publications.

Minkov, M., G. Hofstede., 2012. Is national culture a meaningful concept? Cultural values delineate homogeneous national clusters of in-country regions. Cross-Cultural Research. 46: $133-59$.

Murtha, T., Lenway, S., 1994. Country capabilities and the strategic state: how national 
political institutions affect multinational corporations' strategies. Strategic Management Journal,15: 113-129.

Nair, A., Prajogo, D., 2009. Internalisation of ISO 9000 standards: the antecedent role of functionalist and institutionalist drivers and performance implications. International Journal of Production Research. 47(16), 4545-4568.

Nguyen, B., 2018. Local Institutions on Small Firm Investments: Degree of Institutional Persistence Matter. International Journal of Entrepreneurship and Small Business.26(9), 210-247.

Nguyen, D. K., Phong, L. B., Hui, L., 2019. Creating Competitive Advantage for Vietnamese Manufacturing and Service Firms: The Role of Collaborative Culture and Innovation Capability. International Journal of Business Administration. 10(2), 32-42.

Obal, M., 2017. What drives post-adoption usage? Investigating the negative and positive antecedents of disruptive technology continuous adoption intentions. Industrial Marketing Management. 63(5), 42-52.

Orfila-Sintes, F., Mattsson, J., 2009. Innovation behavior in the hotel industry. Omega, 37(2), 380-394.

Ouyang, Z., Wei, W., Chi, C.G., 2019. Environment management in the hotel industry: does institutional environment matter?. International Journal of Hospitality Management, 77(4), 353-364.

Oyserman, D., Coon, H. M., Kemmelmeier, M., 2002. Rethinking individualism and collectivism: Evaluation of theoretical assumptions and meta-analyses. Psychological Bulletin, 128(1), 3-72.

Palmer, K., Oates, WE., Portney, PR., 1995. Tightening environmental standards: the benefitcost or the no-cost paradigm? Journal of Economic Perspectives. 9(4): 119-132.

Paraskevas, A., Brookes, M., 2018. Human trafficking in hotels: an "invisible" threat for a vulnerable industry. International Journal of Contemporary Hospitality Management. 30(3), 1996-2014.

Park. H, Russell. C, Lee, J., 2007. National culture and environmental sustainability: acrossnational analysis. Journal of Economics and Finance. 31 (1): 104-121.

Pavluković, V., Armenski, T., Alcántara-Pilar, J.M., 2017. Social impacts of music festivals: Does culture impact locals' attitude toward events in Serbia and Hungary?. Tourism Management, 63(1), 42-53.

Petrakis, P.E., Kostis, P.C., Valsamis, D.G., 2015. Innovation and competitiveness: Culture as a long-term strategic instrument during the European Great Recession. Journal of Business Research. 68(7), 1436-1438.

Rabe-Hesketh, S., A. Skrondal., 2008. Multilevel and longitudinal modeling using STATA. College Station, TX: STATA press.

Rahim, M. A., 2014. A structural equations model of leaders' social intelligence and creative performance. Creativity and Innovation Managemen. 23: 44-56.

Ralston, D. A., H. Holt, R. H. Terpstra, Y. Kai-Cheng., 1997. The impact of national culture and economic ideology on managerial work values: A study of the United States, Russia, 
Japan, and China. Journal of International Business Studies. 28 (1): 177-207.

Reischauer, G., 2018. Industry 4.0 as Policy-driven Discourse to Institutionalize Innovation Systems in Manufacturing. Technological Forecasting and Social Change, 132(6), 26-33.

Reynolds, P., Bosma, N., Autio, E., Hunt, S., Bono, N. de, Servais, I., 2005. Global entrepreneurship monitor: Data collection design and implementation 1998-2003. Small Business Economics. 24(3), 205-231.

Rodríguez-Victoria, O.E., Puig, F., González-Loureiro, M., 2017. Clustering, innovation and hotel competitiveness: evidence from the Colombia destination. International Journal of Contemporary Hospitality Management. 29(11), 2785-2806.

Romero, I., Martínez-Román, J.A., 2012. Self-employment and innovation. Exploring the determinants of innovative behavior in small businesses. Research Policy. 41(1),178-189.

Ruhanen, L., Whitford, M., 2018. Racism as an inhibitor to the organisational legitimacy of Indigenous tourism businesses in Australia. Current Issues in Tourism. 21(15), 17281742.

Salunke, S., Weerawardena, J., McColl-Kennedy, J.R., 2019. The central role of knowledge integration capability in service innovation-based competitive strategy. Industrial Marketing Management. 76,144-156.

Sarooghi, H., D. Libaers, A. Burkemper., 2015. Examining the relationship between creativity and innovation: A meta-analysis of organizational, cultural, and environmental factors. Journal of Business Venturing. 30 (5): 714-31

Scott, S. G., Bruce, R., 1994. Determinants of innovative behavior: a path model of individual innovation in the workplace. The Academy of Management Journal. 37(3), 580-607.

Shepherd, C., Ahmed, P.K., 2000. From product innovation to solutions innovation: a new paradigm for competitive advantage. European journal of innovation management. 3(2),100-106.

Sherer, S.A., Meyerhoefer, C.D., Peng, L., 2016. Applying institutional theory to the adoption of electronic health records in the US. Information \& Management. 53(5), 570-580.

Shin, H., Perdue, R.R., Kang, J., 2019. Front desk technology innovation in hotels: A managerial perspective. Tourism Management, 74(6), 310-318.

Sila, I., 2007. Examining the effects of contextual factors on TQM and performance through the lens of organizational theories: An empirical study. Journal of Operations management. 25(1), 83-109.

Skinnarl, K.I., Asa, I., Sharp, P., 2014. Knowledge Sharing (KS), Organizational Learning and Competitive Advantage in a Scandinavian Hotel Company.

Spear, S., 2004. Learning to lead at Toyota. Harvard Business Review. 82 (5): 78

Stamboulis, Y., Skayannis, P., 2003. Innovation strategies and technology for experiencebased tourism. Tourism management. 24(1), 35-43.

Stock, R. M., 2015. Is boreout a threat to frontline employees' innovative work behavior? Journal of Product Innovation Management. 32 (4): 574-92.

Strese, S., Adams, D.R., Flatten, T.C., Brettel, M., 2016. Corporate culture and absorptive 
capacity: The moderating role of national culture dimensions on innovation management. International Business Review. 25(5), 1149-1168.

Suchman, M. C. 1995. Managing Legitimacy: Strategic and Institutional Approaches. Academy of Management Review, 20 (3), 571-610.

Sundbo, J., Orfila-Sintes, F., Sørensen, F., 2007. The innovative behaviour of tourism firmsComparative studies of Denmark and Spain. Research policy. 36(1), 88-106.

Taras, V., Steel, P., Kirkman, B. L., 2012. Improving national cultural indices using a longitudinal meta-analysis of Hofstede's dimensions. Journal of World Business. 47(3), $329-341$.

Tata J, Prasad S., 2015. National cultural values, sustainability beliefs, and organizational initiatives. Cross Cultural Management. 22(2): 278-296

Thomas, A., S. Mueller., 2000. A case for comparative entrepreneurship. Assessing the relevance of culture. Journal of International Business Studies. 31 (2): 287-301.

Tian, M., Deng, P., Zhang, Y., Salmador, M.P., 2018. How does culture influence innovation? A systematic literature review. Management Decision.23(7), 237-258.

Tina Dacin, M., Goodstein, J., Richard Scott, W., 2002. Institutional theory and institutional change: Introduction to the special research forum. Academy of management journal. 45(1), 45-56.

Triandis, H. C., 1994. Culture and social behavior. New York, NY: McGraw-Hill.

Trompenaars, F., Hampden-Turner, C., 1998. Riding the waves of culture: Understanding cultural diversity in global business (2nd ed.). New York, NY: McGraw-Hill.

Urbancova, H., 2013. Competitive advantage achievement through innovation and knowledge. Journal of competitiveness. 5(1), 310-329.

Uzunca, B., Rigtering, J.C., Ozcan, P., 2018. Sharing and shaping: A cross-country comparison of how sharing economy firms shape their institutional environment to gain legitimacy. Academy of management discoveries, 4(3), 248-272.

Verreynne, M.L., Williams, A.M., Ritchie, B.W., Gronum, S., Betts, K.S., 2019. Innovation diversity and uncertainty in small and medium sized tourism firms. Tourism Management. 72, 257-269.

Vitolla, F., Raimo, N., Rubino, M., Garzoni, A., 2019. The impact of national culture on integrated reporting quality. A stakeholder theory approach. Business Strategy and the Environment, 28(8), 1558-1571.

Wang, Y., Font, X., Liu, J., 2020. Antecedents, mediation effects and outcomes of hotel ecoinnovation practice. International Journal of Hospitality Management, 85(6), 102-345.

Wayne, S., L. Shore, R. Liden., 1997. Perceived organizational support and leader-memberexchange: A social exchange perspective. Academy of Management Journal. 40 (1): 82111.

Weerawardena, J., Mavondo, F.T., 2011. Capabilities, innovation and competitive advantage. Industrial Marketing Management. 40(8),1220-1223.

Wei, Z., Shen, H., Zhou, K.Z., Li, J.J., 2017. How does environmental corporate social 
responsibility matter in a dysfunctional institutional environment? Evidence from China. Journal of Business Ethics, 140(2), 209-223.

Wennberg, K., C. Holmquist., 2008. Problemistic Search and International Entrepreneurship. European Management Journal 26 (6), 441-454.

Wikhamn, W., Armbrecht, J., Wikhamn, B.R., 2018. Innovation in Swedish hotels. International Journal of Contemporary Hospitality Management.27(7), 34-51.

Wooldridge, J. M., 2012. Introductory econometrics: A modern approach (5th ed.). Mason, $\mathrm{OH}$ : South-Western Cengage learning.

Wuttke, D.A., Rosenzweig, E.D., Heese, H.S., 2019. An empirical analysis of supply chain finance adoption. Journal of Operations Management. 65(3), 242-261.

Xiang, Z., Magnini, V.P., Fesenmaier, D.R., 2015. Information technology and consumer behavior in travel and tourism: Insights from travel planning using the internet. Journal of Retailing and Consumer Services. 22, 244-249.

Yang, C.S., 2018. An analysis of institutional pressures, green supply chain management, and green performance in the container shipping context. Transportation Research Part D: Transport and Environment. 61(7), 246-260.

Yang, D., Wang, A.X., Zhou, K.Z., Jiang, W., 2019. Environmental strategy, institutional force, and innovation capability: A managerial cognition perspective. Journal of Business Ethics, 159(4), 1147-1161.

Zelezny, LC., Chua, PP., Aldrich, C., 2000. New ways of thinking about environmentalism: elaborating on gender differences in environmentalism. Journal of Social Issues. 56(3): 443-457.

Zhang, X., Xie, L., Li, J., Cheng, L., 2019. Outside in": Global demand heterogeneity and dynamic capabilities of multinational enterprises. Journal of International Business Studies, 23(6), 1-14.

Zhu, Q., Sarkis, J., 2007. The moderating effects of institutional pressures on emergent green supply chain practices and performance. International Journal of Production Research. 45(18-19), 4333-4355.

Zou, H., Xie, X., Qi, G.,Yang, M., 2019. The heterogeneous relationship between board social ties and corporate environmental responsibility in an emerging economy. Business Strategy and the Environment, 28(1), 40-52.

Zvolska, L., Palgan, Y.V., Mont, O., 2019. How do sharing organisations create and disrupt institutions? Towards a framework for institutional work in the sharing economy. Journal of cleaner production, 219(6), 667-676. 